\title{
Plot Erosion Model Using Gray Relational Analysis Method
}

\author{
Q. Q. Liu' ; V. P. Singh, F.ASCE'; and H. Xiang ${ }^{3}$
}

\begin{abstract}
The main factors affecting interrill erosion-including runoff discharge, rainfall intensity, mean flow velocity, and slope gradient-were analyzed by using a gray relational analysis. An equation for interrill erosion was derived by coupling this analysis with dimensional and regression analyses. The values of erosion rates predicted by this equation were in good agreement with experimental observations.
\end{abstract}

DOI: 10.1061/(ASCE)1084-0699(2005)10:4(288)

CE Database subject headings: Erosion; Shear flow; Analytical techniques; Data analysis; Hydrologic models.

\section{Introduction}

Interrill erosion is a complex process, involving detachment of soil particles, transport of soil particles, and resistance of soil to erosion. It is affected by soil and slope characteristics (e.g., soil type, texture, structure, aggregate breakdown, sealing, crusting, and moisture); vegetation and land use; rainfall intensity, event history, and antecedent conditions; and hydraulic factors of runoff (Parsons and Abrahams 1992; Xu et al. 1995; Bradford and Foster 1996). Interrill erosion is caused by sheetflow, rainsplash, and raindrop-enhanced sheetflow; and it reflects the capacity of interrill flow to disperse and transport soil on hillslopes. Raindrop splash detaches soil particles (Rowlinson and Martin 1971; Foster and Meyer 1972), and interrill flow not only detaches but also transports soil particles (Parsons and Abrahams 1992). Soil detachment is the source of interrill erosion. The resistance to erosion is determined by soil characteristics, soil water content, infiltration/exfiltration of soil, pore water pressure, and so on.

A multitude of empirical and semiempirical relationships have been derived for estimating the rate of interrill erosion (Liebenow et al. 1990; Fan and Li 1993; Grosh and Jarrett 1994; Tang and Chen 1994; Sharma et al. 1995; Agassi and Bradford 1995; Bradford and Foster 1996; Zhang et al. 1998; Flanagan and Nearing 2000; Bulygin 2001). Horton (1945) reasoned that the erosion rate of overland flow depended on the difference between the erosion capacity of runoff and the erosion-resisting capacity of soil. Using the Manning resistance formula and sediment

${ }^{1}$ Professor, Institute of Mechanics, Chinese Academy of Sciences, Beijing 100080; Visiting Professor, Dept. of Civil and Environmental Engineering, Louisiana State Univ., Baton Rouge, LA 70803. E-mail: qqliu@imech.ac.cn, qliul@1su.edu

${ }^{2}$ A. K. Barton Professor, Dept. of Civil and Environmental Engineering, Louisiana State Univ., Baton Rouge, LA 70803-6405. E-mail: cesing@1su.edu

${ }^{3}$ Research Assistant, Institute of Mechanics, Chinese Academy of Sciences, Beijing 100080, China.

Note. Discussion open until December 1, 2005. Separate discussions must be submitted for individual papers. To extend the closing date by one month, a written request must be filed with the ASCE Managing Editor. The manuscript for this paper was submitted for review and possible publication on July 11, 2003; approved on October 16, 2004. This paper is part of the Journal of Hydrologic Engineering, Vol. 10, No. 4, July 1, 2005. @ASCE, ISSN 1084-0699/2005/4-288-294/\$25.00. continuity, he derived a formula for the erosion rate of interrill flow as

$$
D_{i}=k_{i} \frac{c \gamma d^{2}}{1,000 d_{0}^{2}}\left(\frac{q_{*} n x}{36}\right)^{3 / 5} \frac{\sin \theta}{(\operatorname{tg} \theta)^{0.3}}
$$

where $k_{i}=$ interrill erodibility of soil; $c$ is a coefficient; $\gamma$ $=$ specific weight of water; $d=$ diameter of soil particles; $d_{0}$ $=$ reference diameter; $q_{*}=$ rainfall excess; $n=$ roughness coefficient, $x=$ distance along slope; and $\theta=$ slope angle.

On the basis of Horton's work, Foster et al. (1981) suggested that the interrill erosion rate was a function of the difference between the flow shear stress and critical erosion-resisting stress. Foster et al. indicated that only when the sediment concentration of runoff was smaller than its transport capacity and when flow shear stress was greater than that required for inception of sediment motion, did soil erosion occur.

Liebenow et al. (1990) developed an empirical model for interrill erosion which was included in the water erosion prediction project (WEPP) model: $D_{i}=k_{i} I^{b} S_{f}$, where $D_{i}=$ interrill erosion rate; $k_{i}=$ interrill erodibility of soil that was assumed to be caused completely by rainfall; $I=$ rainfall intensity, $S_{f}=$ slope factor expressed as $S_{f}=\left(1.05-0.85 e^{-4 \sin \theta}\right)$, in which $\theta=$ slope angle. Sharma et al. (1995) found that the rainfall detachment rate and the transport rate of interrill flow were different because of the redistribution of sediment in the region of interrill. They expressed the interrill erosion rate as $D_{i}=K_{t} I\left(E-E_{0}\right) S_{f}$, where $K_{i}$ $=$ transport capacity of interrill flow; $E=$ kinetic energy of rainfall per unit area; $E_{0}=$ critical kinetic energy leading to soil detachment; and $I$ and $S_{f}$ have same meaning as previously. By using observed data, Bulygin (2001) developed an alternative empirical model of interrill erosion for inclusion in the WEPP model: $D_{i}$ $=k_{i} \cdot I \cdot q \cdot\left(1.05-0.85 e^{-4 \sin \theta}\right)$, where $q=$ unit discharge of overland flow; and where other symbols have the same meaning that they previously had. This model does not fit the experimental data as well as the $I^{2}$ model, but it seems theoretically more reasonable.

Owing to the complexity of the soil-erosion process, the simple and empirical analyses that are based on experimental data are still essential for developing interrill erosion models. The objective of this study is to employ a gray relational analysis method for investigating interrill erosion. In analyzing experimental data by this method, the main factors affecting interrill erosion were analyzed first. Then, through dimensional and regression analyses, an interrill erosion formula was derived. 


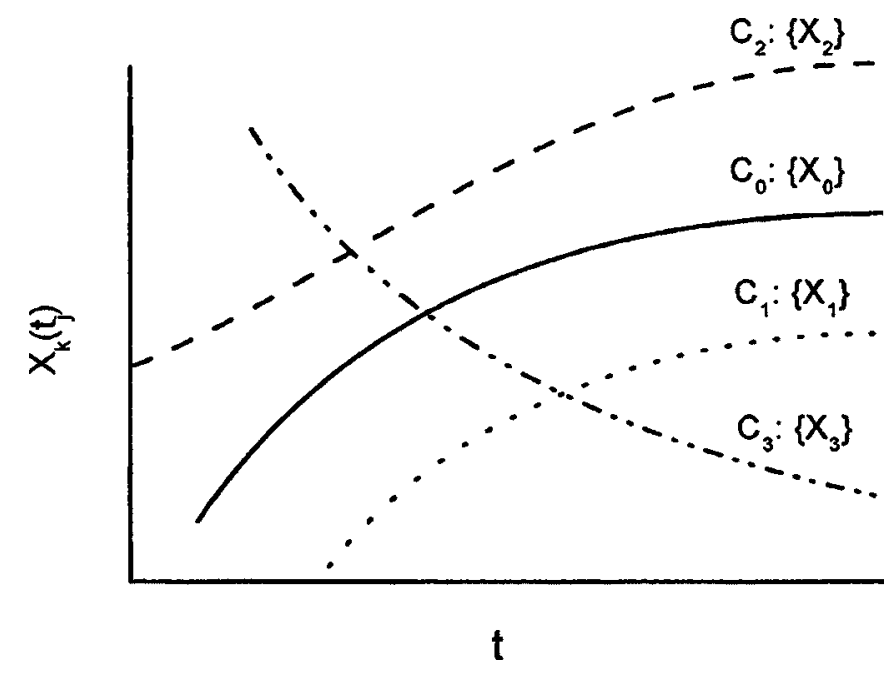

Fig. 1. Sketch of geometric description of four time-data alignments

\section{Gray Relational Analysis Method}

The gray relational analysis, proposed by Deng (1982), is a method that measures the correlation between factors (or variables) and belongs to the category of geometric treatment methods. An important concept in the gray relational system is the gray relational grade, which is a measure of the degree of correlation between two factors. For any factor or variable, there are two alignments $\left\{X_{0}\right\}$ and $\left\{X_{1}\right\}$, which may be time alignments or data alignments. Suppose that $x_{0}(j)$ and $x_{1}(j)$ represent the data at the $j$ point of alignments $\left\{X_{0}\right\}$ and $\left\{X_{1}\right\}$, respectively. Then the average degree of the differences between $\left\{x_{0}(j)\right\}$ and $\left\{x_{1}(j)\right\}(j$ $=1,2,3, \ldots, M)$ at various points is named the gray relational grade of these two alignments or factors. If there is one variable $\left\{X_{0}\right\}$ (system characteristic alignment) and three effect factors $\left\{X_{k}\right\} k=1,2,3$ (factor alignments); that is, four time alignments observed at different times $t_{j}, j=1,2,3, \ldots M$, then one can express

$$
\begin{gathered}
\left\{X_{0}\right\}=\left\{x_{0}\left(t_{1}\right), x_{0}\left(t_{2}\right), \ldots x_{0}\left(t_{M}\right)\right\}, \\
\left\{X_{k}\right\}=\left\{x_{k}\left(t_{1}\right), x_{k}\left(t_{2}\right), \ldots x_{k}\left(t_{M}\right)\right\}, \quad k=1,2,3
\end{gathered}
$$

As shown in Fig. 1, curved line $C_{0}$ consists of alignments $\left\{X_{0}\right\}$ that represent the development process of variable $X_{0}$, and curved lines $C_{k}(k=1,2,3)$ consist of alignments $\left\{X_{k}\right\}$ that represent the development process of factors $X_{k}$. Since curved lines $C_{0}$ and $C_{1}$ are approximately parallel, the difference between them is the smallest; thus, the gray relational grade between two factors, $X_{0}$ and $X_{1}$, measured by $r_{01}$, is identified as the largest. On the other hand, the difference between curve lines $C_{0}$ and $C_{3}$ is the largest, and the gray relational grade between the two factors $X_{0}$ and $X_{3}$, $r_{03}$, is the smallest. Therefore, the gray relational grades can be ordered as $r_{01}>r_{03}>r_{02}$.

This analysis is only a kind of visual analysis that briefly introduces the basic principle of gray relational analysis. The analysis method of judging the gray relational grade between factors is next introduced. Suppose that the data series of one variable and three effect factors are designated as $\left\{x_{0}(j)\right\},\left\{x_{1}(j)\right\},\left\{x_{2}(j)\right\}$, $\left\{x_{3}(j)\right\}(j=1,2, \ldots, M)$, respectively. One can write

$$
\begin{gathered}
x_{0}(j)=\left\{x_{0}(1), x_{0}(2), \ldots x_{0}(M)\right\} \\
x_{k}(j)=\left\{x_{k}(1), x_{k}(2), \ldots x_{k}(M)\right\}, \quad k=1,2,3
\end{gathered}
$$

The gray relational grade of $\left\{x_{0}(j)\right\}$ and $\left\{x_{i}(j)\right\}$ depends on the difference between them at various time points. Because of the difference in the units of $\left\{x_{0}(j)\right\}$ and $\left\{x_{k}(j)\right\}$, it is usually necessary to first make the original data series dimensionless. Dividing each data series by its average gives the following result:

$$
X_{k}(j)=\frac{x_{k}(j)}{\bar{x}_{k}}, \quad \text { here } \quad \bar{x}_{k}=\frac{1}{M} \sum_{j=1}^{M} x_{k}(j)
$$

At point $t_{j}$, the absolute value of the difference between series $\left\{X_{0}(j)\right\}$ and $\left\{X_{k}(j)\right\}$ is

$$
\Delta_{0 k}(j)=\left|X_{0}(j)-X_{k}(j)\right|
$$

The smallest and largest values of the absolute difference at various time points are computed as

$$
\Delta_{\min }=\min _{k} \min _{j} \Delta_{0 k}(j)
$$

$$
\Delta_{\max }=\max _{k} \max _{j} \Delta_{0 k}(j)
$$

The gray relational coefficient of $\left\{X_{k}(j)\right\}$ and $\left\{X_{0}(j)\right\}$ at time $t_{j}$ is now defined as

$$
L_{0 k}(j)=\frac{\Delta_{\min }+\beta \Delta_{\max }}{\Delta_{0 k}(j)+\beta \Delta_{\max }}
$$

where $\beta \in(0,1)$ is an adjustable coefficient. When $\Delta_{0 k}(j)=\Delta_{\min }$, the gray relational coefficient reaches the largest value, $L_{0 k}(j)$ $=1$; when $\Delta_{0 k}(j)=\Delta_{\max }$, the gray relational coefficient has the smallest value:

$$
L_{0 k}(j)=\frac{\Delta_{\min }+\beta \Delta_{\max }}{\Delta_{\max }+\beta \Delta_{\max }}=\frac{1}{1+\beta}\left(\beta+\frac{\Delta_{\min }}{\Delta_{\max }}\right)
$$

The coefficient $\beta$ can adjust the magnitude and the range of the gray relational coefficient $L_{0 k}(j)$. The value of $L_{0 k}(j)$ is always smaller than 1 ; its smallest value increases as $\beta$ increases. In application, different values of the coefficient $\beta$ can be chosen; and in general, $\beta \leqslant 0.5$.

The gray relational coefficient only express the relative degree between data at various points. Because of discrete data points, it is not convenient for comparison. Therefore, the gray relational grade was used to describe the average degree of correlation between two data series. The gray relational grade was defined as

$$
r_{0 k}=\frac{1}{M} \sum_{j=1}^{M} L_{0 k}(j)
$$

The order of gray relational grades is more important than their values. If $r_{0 i}>r_{0 j}$, factor $X_{i}$ is prior to the factor $X_{j}$. Consequently, the importance of factors can be evaluated according to the order of gray relational grades. The advantages of gray relational analysis are that it is computationally efficient, that it does not need large amounts of historical data, and that it facilitates discerning relationship from limited and discrete data. In the past 10 years, this method has been applied successfully in such different fields as engineering, agriculture, soil erosion, management, and so on (Fan 1986; Luo and Xu 1989; Fu 1992; Yi and Guo 1992). 
Table 1. Pertinent Characteristics of Eight Experiments

\begin{tabular}{|c|c|c|c|c|c|c|c|c|}
\hline \multirow[b]{2}{*}{ Characteristics } & \multicolumn{8}{|c|}{ Case } \\
\hline & 1 & 2 & 3 & 4 & 5 & 6 & 7 & 8 \\
\hline Rainfall intensity (mm/h) & 87 & 190 & 60 & 80 & 62 & 157 & 102 & 124 \\
\hline Inclination angle of slope & $15^{\circ}$ & $15^{\circ}$ & $20^{\circ}$ & $20^{\circ}$ & $25^{\circ}$ & $25^{\circ}$ & $30^{\circ}$ & $30^{\circ}$ \\
\hline Initial water content $(\%)$ & 11.64 & 6.97 & 8.6 & 8.6 & 8.64 & 25.04 & 6.07 & 22.06 \\
\hline Water content after test $(\%)$ & 24.92 & 27.17 & $-^{\mathrm{a}}$ & $-^{\mathrm{a}}$ & 26.77 & 32.52 & 22.06 & 23.20 \\
\hline Initial soil bulk density $\left(\mathrm{g} / \mathrm{cm}^{3}\right)$ & 1.49 & 1.40 & 1.2 & 1.2 & 1.37 & 1.63 & 1.39 & 1.72 \\
\hline Soil bulk density after test $\left(\mathrm{g} / \mathrm{cm}^{3}\right)$ & 1.56 & 1.69 & $-^{\mathrm{a}}$ & $-^{\mathrm{a}}$ & 1.62 & 1.68 & 1.72 & 1.73 \\
\hline Water temperature $\left({ }^{\circ} \mathrm{C}\right)$ & 24.2 & 24.0 & 15.0 & 12.0 & 18.0 & 19.0 & 8.0 & 8.0 \\
\hline Time in which rill occurs & $23^{\prime} 30^{\prime \prime}$ & $13^{\prime} 30^{\prime \prime}$ & $61^{\prime} 00^{\prime \prime}$ & $35^{\prime} 00^{\prime \prime}$ & No & $6^{\prime} 15^{\prime \prime}$ & $25^{\prime} 38^{\prime \prime}$ & $3^{\prime} 20^{\prime \prime}$ \\
\hline
\end{tabular}

${ }^{\mathrm{a}}$ The value was not observed in the experiments.

\section{Gray Relational Analysis for Experimental Data of Interrill Erosion}

\section{Experimental Data}

A series of experiments was conducted on a test plot with artificial rainfall at the National Key Laboratory of Soil Erosion and Dryland Farming in Loess Plateau in Yangling, Shanxi Province, People's Republic of China. The test plot was a $3.2 \mathrm{~m}$ long, $1.0 \mathrm{~m}$ wide and $0.3 \mathrm{~m}$ deep wooden box with holes at the bottom that provide free drainage and prevent water-table development. Rainfall was simulated by a drop-former-type rainfall simulator, in which raindrops were formed at an average height of $16 \mathrm{~m}$ and that produced drop-size distributions similar to natural rainfall. The rainfall intensity was automatically adjusted in the range of $15-200 \mathrm{~mm} / \mathrm{h}$ according to the requirements of the experiment. (In field experiments, rainfall of this intensity was commonly observed by four rain gauges in Yangling.) The soil used in the experiments was the local loess of Yangling in Shanxi province.

In the experiments, runoff discharge, sediment concentration, and the quantity of soil eroded were measured at the outlet of the test plot by continuously collecting runoff samples collected at different times. The flow velocities at several specific points were also measured by a dye tracer method. When using the dye method, the velocity associated with the peak concentration was assumed to equal the mean velocity of overland flow. However, determining the peak concentration visually was difficult. In practice, the leading edge of the tracer was used and then a correction factor of 0.66 was applied. Because of the difficulty of observation, the depth of runoff was not measured but was calculated numerically by using the kinematic wave model (Liu and Singh 2004). Since rills developed in most of the experiments, the time to the occurrence of rills was also observed. Eight sets of experiments for different rainfall intensities in the range of 60 to $190 \mathrm{~mm} / \mathrm{h}$ and four slope gradients were conducted. Table 1 gives pertinent characteristics of these eight experiments (cases).

The experimental results of runoff discharges and accumulated erosion amounts, as shown in Fig. 2, indicated that when rills occurred on the slope, the quantity of soil eroded rapidly increased. Except during the fifth experiment, rill erosion occurred during experiments. Therefore, experimental data before the occurrence of rill erosion were selected for each test to analyze the process of interrill erosion, although distinguishing between concentrated sheetflow and dispersed sheetflow was difficult. In total, 29 groups of data were assembled to evaluate
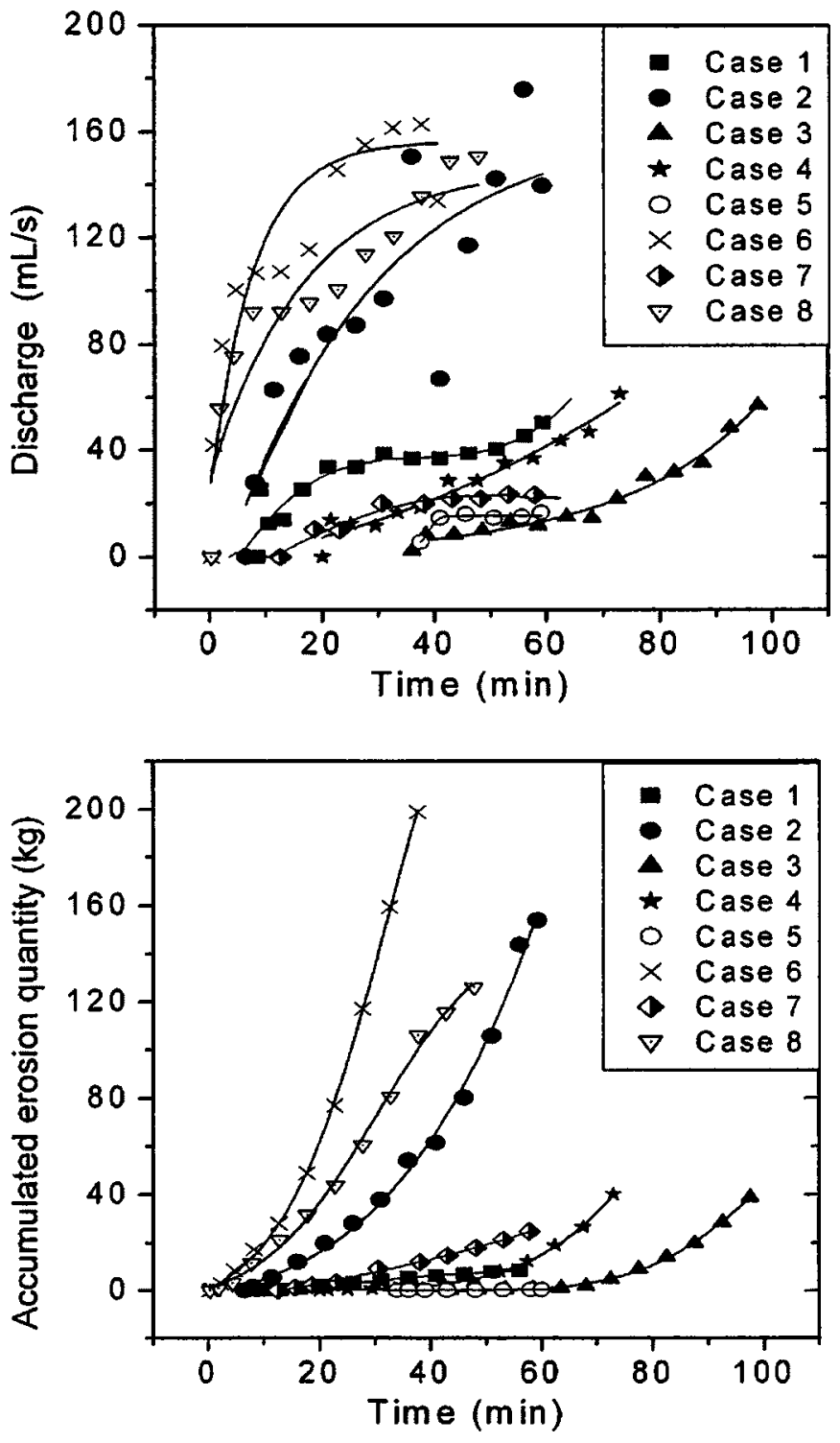

Fig. 2. Experimental results: (a) Discharge versus time and (b) accumulated erosion quantity versus time 
Table 2. Gray Relational Analysis on the Experimental Data

\begin{tabular}{|c|c|c|c|c|c|c|c|c|c|}
\hline $\begin{array}{l}\text { Sediment } \\
\text { concentration } \\
(0.01 \mathrm{~g} / \mathrm{mL}) \\
\end{array}$ & $\begin{array}{c}\text { Average } \\
\left\{X_{0}(j)\right\}\end{array}$ & $\begin{array}{c}\text { Runoff } \\
\text { discharge } \\
\left(\mathrm{cm}^{3} / \mathrm{s}\right) \\
\end{array}$ & $\begin{array}{c}\text { Average } \\
\left\{X_{1}(j)\right\}\end{array}$ & $\begin{array}{c}\text { Differences } \\
\text { of series } \\
\left\{\Delta_{01}(j)\right\} \\
\end{array}$ & $\begin{array}{c}\text { Gray } \\
\text { relational } \\
\text { coefficient } \\
\left\{L_{01}(j)\right\}\end{array}$ & $\begin{array}{l}\text { Rainfall } \\
\text { intensity } \\
(\mathrm{mm} / \mathrm{min}) \\
\end{array}$ & $\begin{array}{c}\text { Average } \\
\left\{X_{2}(j)\right\}\end{array}$ & $\begin{array}{c}\text { Differences } \\
\text { of series } \\
\left\{\Delta_{02}(j)\right\} \\
\end{array}$ & $\begin{array}{c}\text { Gray } \\
\text { relational } \\
\text { coefficient } \\
\left\{L_{02}(j)\right\}\end{array}$ \\
\hline 2.00 & 0.16 & 8.37 & 0.34 & 0.18 & 0.90 & 1.00 & 0.64 & 0.48 & 0.77 \\
\hline 3.64 & 0.30 & 8.37 & 0.34 & 0.05 & 0.97 & 1.00 & 0.64 & 0.34 & 0.82 \\
\hline 3.16 & 0.26 & 10.05 & 0.41 & 0.16 & 0.91 & 1.00 & 0.64 & 0.38 & 0.80 \\
\hline 3.67 & 0.30 & 13.40 & 0.55 & 0.25 & 0.86 & 1.00 & 0.64 & 0.34 & 0.82 \\
\hline 5.95 & 0.49 & 11.72 & 0.48 & 0.00 & 1.00 & 1.00 & 0.64 & 0.16 & 0.91 \\
\hline 5.68 & 0.46 & 13.96 & 0.57 & 0.11 & 0.93 & 1.34 & 0.86 & 0.40 & 0.80 \\
\hline 5.77 & 0.47 & 12.56 & 0.52 & 0.05 & 0.97 & 1.34 & 0.86 & 0.39 & 0.80 \\
\hline 5.19 & 0.42 & 11.72 & 0.48 & 0.06 & 0.96 & 1.34 & 0.86 & 0.44 & 0.78 \\
\hline 6.10 & 0.50 & 16.75 & 0.69 & 0.19 & 0.89 & 1.34 & 0.86 & 0.36 & 0.81 \\
\hline 44.82 & 3.66 & 20.93 & 0.86 & 2.79 & 0.36 & 1.71 & 1.10 & 2.56 & 0.38 \\
\hline 43.47 & 3.55 & 10.47 & 0.43 & 3.11 & 0.33 & 1.71 & 1.10 & 2.45 & 0.39 \\
\hline 41.60 & 3.39 & 10.05 & 0.41 & 2.98 & 0.34 & 1.71 & 1.10 & 2.30 & 0.40 \\
\hline 8.13 & 0.66 & 55.80 & 2.30 & 1.63 & 0.49 & 2.06 & 1.32 & 0.66 & 0.70 \\
\hline 3.41 & 0.28 & 12.56 & 0.52 & 0.24 & 0.87 & 1.04 & 0.67 & 0.39 & 0.80 \\
\hline 2.74 & 0.22 & 5.58 & 0.23 & 0.01 & 1.00 & 1.04 & 0.67 & 0.44 & 0.78 \\
\hline 2.06 & 0.17 & 14.65 & 0.60 & 0.43 & 0.78 & 1.04 & 0.67 & 0.50 & 0.76 \\
\hline 1.24 & 0.10 & 18.05 & 0.74 & 0.64 & 0.71 & 1.04 & 0.67 & 0.57 & 0.73 \\
\hline 1.74 & 0.14 & 11.72 & 0.48 & 0.34 & 0.82 & 1.04 & 0.67 & 0.53 & 0.75 \\
\hline 2.07 & 0.17 & 15.07 & 0.62 & 0.45 & 0.78 & 1.04 & 0.67 & 0.50 & 0.76 \\
\hline 17.06 & 1.39 & 41.87 & 1.72 & 0.33 & 0.82 & 2.62 & 1.68 & 0.29 & 0.84 \\
\hline 25.91 & 2.11 & 79.55 & 3.27 & 1.16 & 0.57 & 2.62 & 1.68 & 0.43 & 0.78 \\
\hline 31.18 & 2.54 & 100.50 & 4.14 & 1.59 & 0.49 & 2.62 & 1.68 & 0.86 & 0.64 \\
\hline 27.57 & 2.25 & 27.91 & 1.15 & 1.10 & 0.59 & 3.16 & 2.03 & 0.22 & 0.87 \\
\hline 26.75 & 2.18 & 62.80 & 2.58 & 0.40 & 0.79 & 3.16 & 2.03 & 0.16 & 0.91 \\
\hline 4.91 & 0.40 & 25.12 & 1.03 & 0.63 & 0.71 & 1.45 & 0.93 & 0.53 & 0.75 \\
\hline 4.31 & 0.35 & 12.56 & 0.52 & 0.17 & 0.90 & 1.45 & 0.93 & 0.58 & 0.73 \\
\hline 5.59 & 0.46 & 13.96 & 0.57 & 0.12 & 0.93 & 1.45 & 0.93 & 0.47 & 0.77 \\
\hline 8.75 & 0.71 & 25.12 & 1.03 & 0.32 & 0.83 & 1.45 & 0.93 & 0.22 & 0.88 \\
\hline 10.96 & 0.89 & 33.49 & 1.38 & 0.48 & 0.76 & 1.45 & 0.93 & 0.04 & 0.98 \\
\hline \multicolumn{7}{|c|}{ Gray relational grade $r_{01}=0.78$} & \multicolumn{3}{|c|}{ Gray relational grade $r_{02}=0.76$} \\
\hline \multicolumn{10}{|c|}{ (b) Mean flow velocity and slope gradient } \\
\hline $\begin{array}{l}\text { Mean } \\
\text { velocity } \\
(\mathrm{cm} / \mathrm{s}) \\
\end{array}$ & $\begin{array}{c}\text { Average } \\
\left\{X_{3}(j)\right\}\end{array}$ & $\begin{array}{c}\text { Differences } \\
\text { of series } \\
\left\{\Delta_{03}(j)\right\}\end{array}$ & $\begin{array}{c}\text { Gray } \\
\text { relational } \\
\text { coefficient } \\
\left\{L_{03}(j)\right\}\end{array}$ & & $\begin{array}{l}\text { Slope } \\
\text { gradient } \\
\text { (degree) }\end{array}$ & $\begin{array}{c}\text { Average } \\
\left\{X_{4}(j)\right\}\end{array}$ & $\begin{array}{c}\text { Differences } \\
\text { of series } \\
\left\{\Delta_{04}(j)\right\}\end{array}$ & $\begin{array}{c}\text { Gray } \\
\text { relational } \\
\text { coefficient } \\
\left\{L_{04}(j)\right\}\end{array}$ & \\
\hline 6.25 & 0.43 & 0.27 & 0.85 & & 20.00 & 0.92 & 0.76 & 0.67 & \\
\hline 6.70 & 0.46 & 0.17 & 0.90 & & 20.00 & 0.92 & 0.62 & 0.71 & \\
\hline 7.09 & 0.49 & 0.23 & 0.87 & & 20.00 & 0.92 & 0.66 & 0.70 & \\
\hline 8.62 & 0.60 & 0.30 & 0.84 & & 20.00 & 0.92 & 0.62 & 0.71 & \\
\hline 7.37 & 0.51 & 0.03 & 0.98 & & 20.00 & 0.92 & 0.44 & 0.78 & \\
\hline 11.11 & 0.77 & 0.31 & 0.84 & & 20.00 & 0.92 & 0.46 & 0.77 & \\
\hline 12.04 & 0.83 & 0.36 & 0.81 & & 20.00 & 0.92 & 0.45 & 0.78 & \\
\hline 12.81 & 0.89 & 0.47 & 0.77 & & 20.00 & 0.92 & 0.50 & 0.76 & \\
\hline 10.97 & 0.76 & 0.26 & 0.86 & & 20.00 & 0.92 & 0.42 & 0.79 & \\
\hline 10.91 & 0.76 & 2.90 & 0.35 & & 30.00 & 1.38 & 2.27 & 0.41 & \\
\hline 15.00 & 1.04 & 2.51 & 0.38 & & 30.00 & 1.38 & 2.16 & 0.42 & \\
\hline 9.53 & 0.66 & 2.73 & 0.36 & & 30.00 & 1.38 & 2.01 & 0.44 & \\
\hline 20.73 & 1.44 & 0.77 & 0.67 & & 30.00 & 1.38 & 0.72 & 0.68 & \\
\hline 8.38 & 0.58 & 0.30 & 0.84 & & 25.00 & 1.15 & 0.87 & 0.64 & \\
\hline 7.92 & 0.55 & 0.33 & 0.83 & & 25.00 & 1.15 & 0.93 & 0.63 & \\
\hline 8.23 & 0.57 & 0.40 & 0.79 & & 25.00 & 1.15 & 0.98 & 0.61 & \\
\hline 7.80 & 0.54 & 0.44 & 0.78 & & 25.00 & 1.15 & 1.05 & 0.60 & \\
\hline
\end{tabular}


(b) Mean flow velocity and slope gradient

\begin{tabular}{|c|c|c|c|c|c|c|c|}
\hline $\begin{array}{l}\text { Mean } \\
\text { velocity } \\
(\mathrm{cm} / \mathrm{s})\end{array}$ & $\begin{array}{c}\text { Average } \\
\left\{X_{3}(j)\right\}\end{array}$ & $\begin{array}{c}\text { Differences } \\
\text { of series } \\
\left\{\Delta_{03}(j)\right\}\end{array}$ & $\begin{array}{c}\text { Gray } \\
\text { relational } \\
\text { coefficient } \\
\left\{L_{03}(j)\right\} \\
\end{array}$ & $\begin{array}{c}\text { Slope } \\
\text { gradient } \\
\text { (degree) }\end{array}$ & $\begin{array}{c}\text { Average } \\
\left\{X_{4}(j)\right\}\end{array}$ & $\begin{array}{c}\text { Differences } \\
\text { of series } \\
\left\{\Delta_{04}(j)\right\}\end{array}$ & $\begin{array}{c}\text { Gray } \\
\text { relational } \\
\text { coefficient } \\
\left\{L_{04}(j)\right\}\end{array}$ \\
\hline 8.51 & 0.59 & 0.45 & 0.78 & 25.00 & 1.15 & 1.01 & 0.61 \\
\hline 9.91 & 0.69 & 0.52 & 0.75 & 25.00 & 1.15 & 0.98 & 0.61 \\
\hline 15.63 & 1.08 & 0.31 & 0.83 & 25.00 & 1.15 & 0.24 & 0.87 \\
\hline 17.81 & 1.24 & 0.88 & 0.64 & 25.00 & 1.15 & 0.96 & 0.62 \\
\hline 20.01 & 1.39 & 1.16 & 0.57 & 25.00 & 1.15 & 1.39 & 0.53 \\
\hline 32.65 & 2.26 & 0.02 & 0.99 & 15.00 & 0.69 & 1.56 & 0.50 \\
\hline 34.27 & 2.38 & 0.19 & 0.89 & 15.00 & 0.69 & 1.49 & 0.51 \\
\hline 15.17 & 1.05 & 0.65 & 0.71 & 15.00 & 0.69 & 0.29 & 0.84 \\
\hline 22.22 & 1.54 & 1.19 & 0.57 & 15.00 & 0.69 & 0.34 & 0.82 \\
\hline 22.22 & 1.54 & 1.09 & 0.59 & 15.00 & .69 & 0.23 & 0.87 \\
\hline 24.24 & 1.68 & 0.97 & 0.62 & 15.00 & 0.69 & 0.02 & 0.99 \\
\hline 24.22 & 1.68 & 0.79 & 0.66 & 15.00 & 0.69 & 0.20 & 0.88 \\
\hline \multicolumn{4}{|c|}{ Gray relational grade $r_{03}=0.74$} & \multicolumn{4}{|c|}{ Gray relational grade $r_{04}=0.68$} \\
\hline
\end{tabular}

the performance of interrill erosion. The runoff discharge ranged from 6.25 to $34.27 \mathrm{~mL} / \mathrm{s}$ and the sediment concentration of runoff varied from 0.02 to $0.45 \mathrm{~g} / \mathrm{mL}$.

\section{Gray Relational Analysis of Experimental Data}

The data series of sediment concentration, runoff discharge, rainfall intensity, mean flow velocity, and slope gradient were designated as $\left\{x_{0}(j)\right\},\left\{x_{1}(j)\right\},\left\{x_{2}(j)\right\}, \quad\left\{x_{3}(j)\right\}$, and $\left\{x_{4}(j)\right\} \quad(j$ $=1,2, \ldots M)$, respectively, and were analyzed by using the gray relational analysis as follows:

1. The average value of the sediment concentration was obtained as

$$
\overline{x_{0}}=\frac{1}{29} \sum_{j=1}^{29} x_{0}(j)=0.123(\mathrm{~g} / \mathrm{mL})
$$

Similarly, $\overline{x_{1}}=2.43 \times 10^{-5}\left(\mathrm{~m}^{3} / \mathrm{s}\right), \overline{x_{2}}=2.6 \times 10^{-5}(\mathrm{~m} / \mathrm{s}), \overline{x_{3}}$ $=0.1442(\mathrm{~m} / \mathrm{s})$, and $\overline{x_{4}}=21.72$. We let $X_{k}(j)=x_{k}(j) / \overline{x_{k}}, k$ $=0,1,2,3,4$. Then the new dimensionless data series $\left\{X_{0}(j)\right\}$, $\left\{X_{1}(j)\right\},\left\{X_{2}(j)\right\},\left\{X_{3}(j)\right\},\left\{X_{4}(j)\right\}$ was generated.

2. The differences of series $\left\{\Delta_{0 k}(j)\right\}$ and their largest and smallest values were obtained as

$$
\begin{gathered}
\Delta_{0 k}(j)=\left|X_{0}(j)-X_{k}(j)\right| \\
\Delta_{\max }=\max _{k} \max _{j}\left|X_{k}(j)-X_{0}(j)\right|=3.12 \\
\Delta_{\text {min }}=\min _{k} \min _{j}\left|X_{k}(j)-X_{0}(j)\right|=0
\end{gathered}
$$

3. The gray relational coefficient $\left\{L_{0 k}(j)\right\}, k=1,2,3,4$, was calculated as

$$
L_{0 k}(j)=\frac{\Delta_{\min }+\beta \Delta_{\max }}{\Delta_{0 k}(j)+\beta \Delta_{\max }}
$$

here taking $\Delta_{\min }=0, \beta, 0.5$.

4. The gray relational grade was calculated as

$$
r_{01}=\frac{1}{29} \sum_{j=1}^{29} L_{01}(j)=0.78
$$

and $r_{02}=0.76, r_{03}=0.74, r_{04}=0.68$.

5. The order of gray relational grades: $r_{01}>r_{02}>r_{03}>r_{04}$ was obtained. The details of the calculation are shown in Table 2.

This result shows the degree of importance of four factors affecting the runoff sediment concentration. It indicates that the order of importance is runoff discharge $>$ rainfall intensity $>$ flow velocity $>$ slope gradient. Thus, from the various hydraulic factors, the runoff discharge may be chosen as the main factor. In the kinematic wave analysis, it is customary to have $q=\alpha h^{m}$, (where $q=$ unit discharge of runoff; $h=$ flow depth; $\alpha=$ coefficient; and $m=$ exponent), so that runoff discharge can be replaced by flow depth. This outcome can also be explained from $\tau=\gamma h S_{f}$, where $\tau=$ flow shear stress; $\gamma=$ specific weight of water; and $S_{f}$ = slope of water surface approximated generally by bed slope gradient $S_{0}$. The depth of runoff and the slope gradient determine the shear stress of overland flow and the eroding capacity of the runoff.

\section{Deriving Formula for Interrill Erosion}

Since only one kind of soil was used in the experiments, the influence of soil characteristics was not considered in the preceding analysis. In reality, such soil characteristics as the diameter and size distribution of soil particles and the aggregate stability of soil (or cohesion) strongly affect soil erosion. In addition, for steep slopes, the ability of interrill flow to detach and transport sediment is rather high, which commonly causes rill erosion on these slopes. The following four factors are the main ones that affect the interrill erosion rate, $D_{i}\left(\mathrm{~kg} / \mathrm{m}^{2} \cdot \mathrm{s}\right)$ : the sediment transport capacity of runoff, $T_{c}(\mathrm{~kg} / \mathrm{m} \cdot \mathrm{s})$; the median grain size of soil particles $d_{50}(\mathrm{~m})$; the runoff depth $h(\mathrm{~m})$; and the slope factor $S_{f}$. Here, the slope factor, $S_{f}$, is used to express the influence of the slope gradient as $S_{f}=1.05-0.85 e^{-4 \sin \theta}$.

By selecting $d_{50}$ and $T_{c}$ as the basic variables and making the preceding factors dimensionless, we can obtain three dimensionless parameters. They are $D_{i} d_{50} / T_{c}, h / d_{50}$, and $S_{f}$. We assume that the following functional relationship exists: 
Table 3. Median Grain Size, Grain Roughness and Corresponding Critical Shear Stress

\begin{tabular}{lccccc}
\hline & $A$ & $B$ & $C$ & $D$ & $E$ \\
\hline $\begin{array}{l}\text { Median grain size } \\
D_{50}(\mu \mathrm{m})\end{array}$ & 58 & 127 & 218 & 414 & 1,098 \\
$\begin{array}{l}\text { Grain roughness } \\
k_{s}(\mu \mathrm{m})\end{array}$ & 60 & 140 & 250 & 500 & 1,200 \\
$\tau_{c r}(\mathrm{~Pa})$ & 0.20 & 0.25 & 0.27 & 0.30 & 0.35 \\
\hline
\end{tabular}

$$
\frac{D_{i} d_{50}}{T_{c}}=f\left(\frac{h}{d_{50}}, S_{f}\right)
$$

Since hillslopes on the Loess Plateau generally have steep slopes, the experimental plots also had steep slopes. Low (1989) derived a formula for estimating the sediment-transport capacity of runoff on steep slopes. This formula was therefore employed as follows:

$$
T_{c}=\frac{6.42}{(s-1)^{0.45}}\left(Y-Y_{c r}\right) d S^{0.6} u \rho_{s}
$$

where $Y=$ dimensionless flow shear stress, $\quad Y=\tau / \gamma_{s}{ }^{*} d ; Y_{c r}$ $=$ dimensionless critical shear stress, $Y_{c r}=\tau_{c r} / \gamma_{s}{ }^{*} d ; \tau=$ flow shear stress $\left(\mathrm{N} / \mathrm{m}^{2}\right), \quad \tau=\rho g R S ; \quad \gamma_{s}{ }^{*}=\left(\rho_{s}-\rho\right) g, \quad \rho=$ density of water $\left(\mathrm{kg} / \mathrm{m}^{3}\right) ; \rho_{s}=$ density of soil particles $\left(\mathrm{kg} / \mathrm{m}^{3}\right), g=$ gravitational acceleration $\left(\mathrm{m} / \mathrm{s}^{2}\right) ; R=$ hydraulic radius $(\mathrm{m}) ; S$ is the energy slope, (which was approximated by bed slope); $d=$ diameter of sediment particles $(\mathrm{m}), s=\rho_{s} / \rho ; u=$ mean velocity of runoff $(\mathrm{m} / \mathrm{s})$; and $\tau_{c r}$ is the critical shear stress $\left(\mathrm{N} / \mathrm{m}^{2}\right)$, which was obtained from Govers's (1987) results. In Table 3, the results were obtained by collecting data on a wide range of slopes, discharges, and materials, although not all possible conditions were covered in the experiments.

Stepwise multiple regression analyses were performed by using the experimental data. They yielded the following equation:

$$
\frac{D_{i} \cdot d_{50}}{T_{c}}=1.8 \times 10^{-9}\left(\frac{h}{d_{50}}\right)^{1.5} S_{f}
$$

Here, $h$ was numerically calculated by using the kinematic wave model of overland flow on hillslopes (Liu and Singh 2004)

\section{Model Verification}

Eq. (16) was employed to predict the interrill erosion rate. Fig. 3 shows a comparison of the predicted values and observed interrill erosion rates for all our experimental observations. In Fig. 3, the correlation coefficient is $r=0.92$. The high value of the correlation coefficient shows a reasonable agreement between observed and predicted interrill erosion results and indicates that the model is capable of simulating interrill erosion for loess soil in northwest China. For small flow depths, experimental data were scattered, and the agreement between predicted and observed values was not as good. This result may have occurred because there are larger surface roughness elements and strong stochastic elements under conditions of small runoff depth. In addition, the measurement error may be relatively greater when the runoff discharge (or runoff depth) is very small.

Since the experimental data used are limited in several aspects-including as the number of data, the range of variation of rainfall intensity and amount, and types of soil-this study is less than definitive but does show the potential of the gray relational analysis method. Nevertheless, the results of this study are

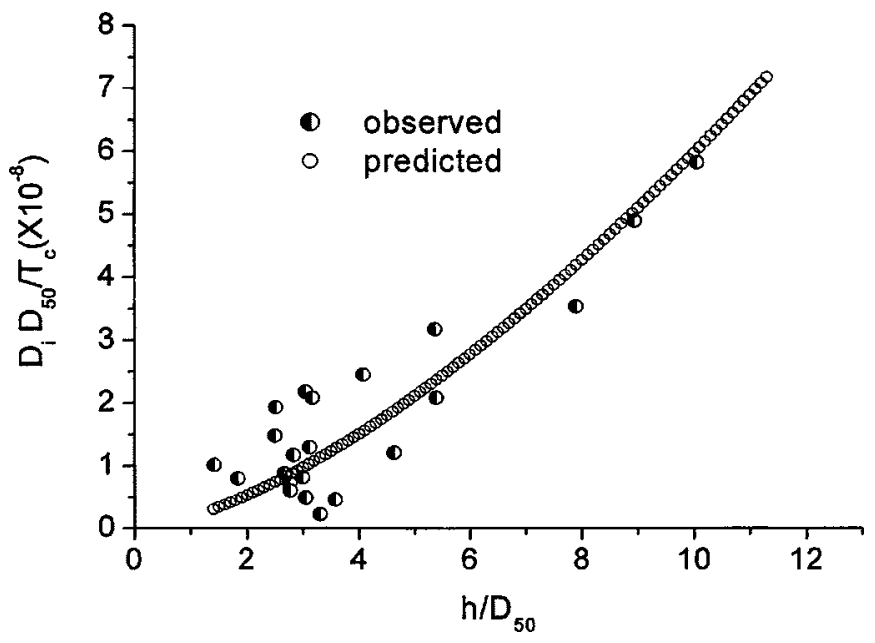

Fig. 3. Observed and predicted interrill erosion rates (correlation coefficient is $r=0.92$ )

encouraging and indicate that gray relational analysis is a potential tool for factors analyzing that affect soil erosion.

\section{Concluding Remarks}

Gray relational analysis is a potentially powerful tool for analyzing the main factors that affect interrill erosion. It is especially useful when there are only limited experimental data-the method permits discerning the main factors from limited data and can provide a credible foundation for further regression analyses. The gray relational analysis of the experimental data pointed out that the gray relational grade of the water discharge (or depth) and sediment transport rate is the largest factor and is then followed by rainfall intensity, flow velocity, and slope gradient. Discriminating the relative importance of the controlling factors in this manner permits the use of dimensional and regression analyses for deriving an interrill erosion formula. The values predicted by this formula are in good agreement with observed values.

\section{Acknowledgment}

This research was financially supported by the Key Projects of the Chinese Natural Science Foundation (No. 10332050 and No. 19832060).

\section{Notation}

The following symbols are used in the paper:

$B=$ exponent;

$C=$ sediment concentration;

$C_{i}=$ curved line, $i=0,1,2, \ldots$;

$c=$ coefficient;

$D_{i}=$ interrill erosion rate;

$d=$ diameter of sediment particles;

$d_{0}=$ reference diameter;

$d_{50}=$ median grain size of soil particles;

$E=$ kinetic energy of rainfall per unit area;

$E_{0}=$ critical kinetic energy leading to soil detachment;

$g=$ acceleration because of gravity; 


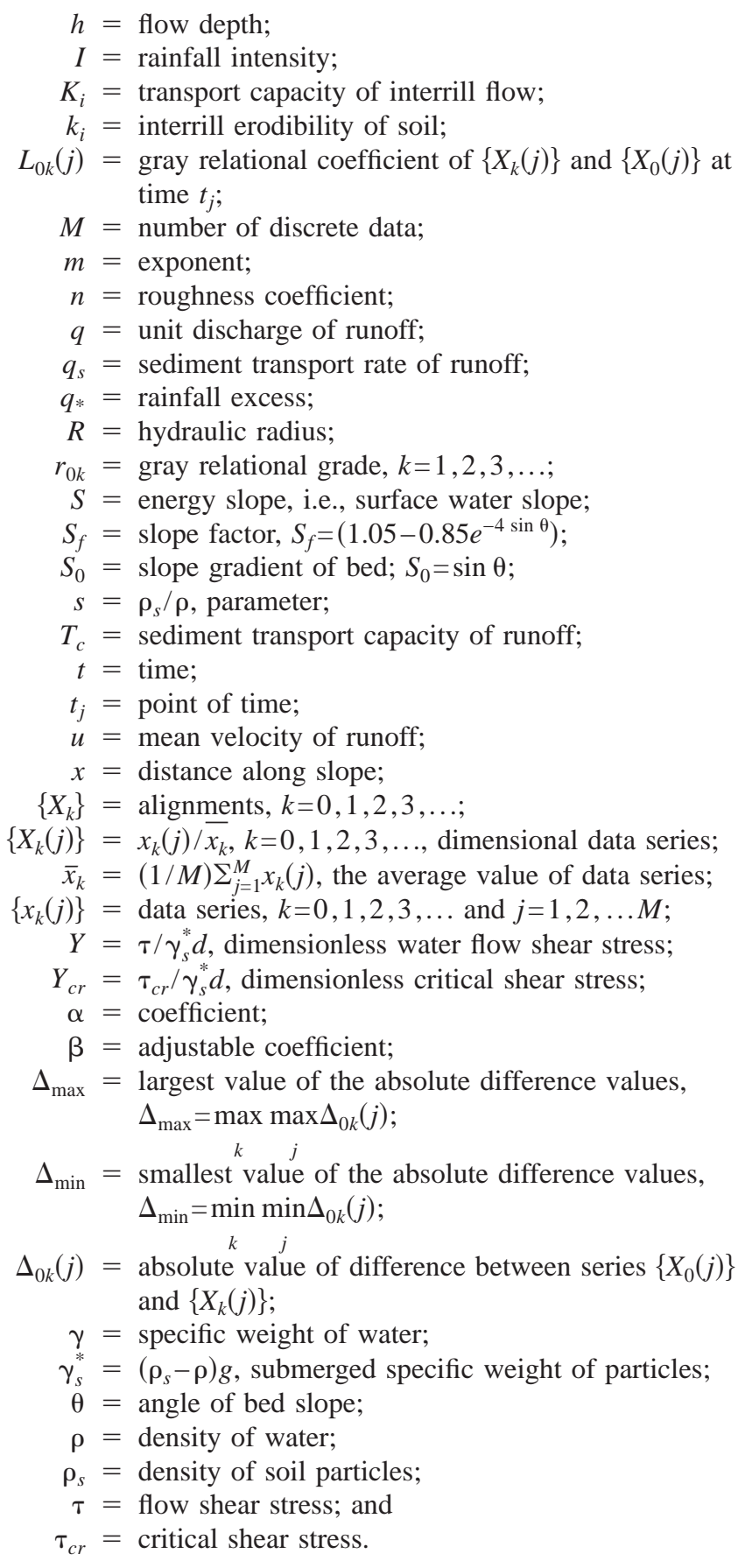

\section{References}

Agassi, M., and Bradford, J. M. (1995). "Methodologies for interrill soil erosion studies." Soil and Tillage Research, 49, 277-287.

Bradford, J. M., and Foster, G. R. (1996). "Interrill soil and slope steepness factors." Soil Sci. Soc. Am. J., 60, 909-915.

Bulygin, S. Y. (2001). "Challenges and approaches for WEPP interrill erodibility measurements in the Ukraine." Proc., Soil Erosion for the 21 st Century Int. Symp. Honolulu, Hawaii, ASAE, St. Joseph, Mich., 506-509.

Deng, J. L. (1982). "The control problems of Grey system." Syst. Control Lett., 5, 288-294.

Fan, L. Y. (1986). "Analyzing on the benefit of soil and water conservation by using grey system theory." Soil and Water Conservation Bulletin, 2, 89-92.

Fan, R. S., and Li, Z. B. (1993). "Model of raindrop splash erosion and sediment transport in hillslopes." J. Hydraul. Eng., 6, 24-29 (in Chinese).

Flanagan, D. C., and Nearing, M. A. (2000). "Sediment particle sorting on hillslope profiles in the WEPP model." Trans. ASAE, 43, 573-583.

Foster, G. R., Lane, L. J., Nowlin, J. D., Laflen, J. M., and Young, R. A. (1981). "Estimating erosion and sediment yield on field-sized areas." Trans. ASAE, 24, 1253-1262.

Foster, G. R., and Meyer, L. D. (1972). "A closed-form soil erosion equation for upland areas." Sedimentation Symp. to Honor Professor H. A. Einstein, H. W. Shen, ed., Colorado State Univ., Fort Collins, Colo., 12.1-12.19.

Fu, L. (1992). Grey system theory and application, Science and Technology Press, Beijing (in Chinese).

Govers, G. (1987). "Initiation of motion in overland flow." Sedimentology, 34, 1157-1164.

Grosh, J. L., and Jarrett, A. R. (1994). "Interrill erosion and runoff on various steep slopes." Trans. ASAE, 37(4), 1127-1133.

Horton, R. E. (1945). "Erosional development of streams and their drainage basins: Hydrological approach to quantitative morphology." Bull. Gel. Soc. Am., 56(3), 275-370.

Liebenow, A. M., Elliot, W. J., Laflen, J. M., and Kohl, K. D. (1990). "Interrill erodibility: Collection and analysis of data from cropland soils." Trans. ASAE, 33, 1882-1888.

Liu, Q. Q., and Singh, V. P. (2004). "Effect of microtopography, slope length and gradient and vegetative cover on overland flow through simulation." J. Hydrologic Eng. 9(5), 375-382.

Low, H. S. (1989). "Effect of sediment density on bed load transport." $J$. Hydraul. Eng., 115(1), 124-138.

Luo, Q. C., and Xu, G. X. (1989). Grey relational analysis and application, Jiangsu Science and Technology Press, Nanjing, China (in Chinese).

Parsons, A. J., and Abrahams, A. D. (1992). "Field investigations of sediment removal in interrill overland flow." Overland flow, A. J. Parsons and A. D. Abrahams, eds., UCL Press, 307-334.

Rowlison, D. L., and Martin, G. L. (1971). "Rational model describing slope erosion." J. Irrig. and Drain. Div., 97(1), 39-50.

Sharma, P. P., Gupta, S. C., and Foster, G. R. (1995). "Raindrop-induced soil detachment and sediment transport from interrill areas." Soil Sci. Soc. Am. J., 59, 727-734.

Tang, L. Q., and Chen, G. Q. (1994). "The formula of soil erosion in the slope and its application in the calculation of watershed sediment yield." Adv. Water Sci., 5(2), 104-110 (in Chinese).

Xu, W. Q., Ni, J. R., Xu, H. P., and Jin, D. S. (1995). "Experimental study on the soil erosion process in the loess slopes." J. Soil Erosion Soil Water Conserv., 9(3), 9-18 (in Chinese).

Yi, D. S., and Guo, P. (1992). Grey theory and method: abstract, subject, technique and application. Oil Industry Press, Beijing (in Chinese).

Zhang, X. C., Nearing, M. A., Miller, W. P., Norton, L. D., and West, L. T. (1998). "Modeling interrill sediment delivery." Soil Sci. Soc. Am. J., 62(2), 438-444. 